\title{
Analysis of surface soil moisture patterns in agricultural landscapes using Empirical Orthogonal Functions
}

\author{
W. Korres, C. N. Koyama, P. Fiener, and K. Schneider \\ Department of Geography, University of Cologne, Cologne, Germany \\ Received: 30 July 2009 - Published in Hydrol. Earth Syst. Sci. Discuss.: 24 August 2009 \\ Revised: 3 April 2010 - Accepted: 14 April 2010 - Published: 12 May 2010
}

\begin{abstract}
Soil moisture is one of the fundamental variables in hydrology, meteorology and agriculture. Nevertheless, its spatio-temporal patterns in agriculturally used landscapes that are affected by multiple natural (rainfall, soil, topography etc.) and agronomic (fertilisation, soil management etc.) factors are often not well known. The aim of this study is to determine the dominant factors governing the spatiotemporal patterns of surface soil moisture in a grassland and an arable test site that are located within the Rur catchment in Western Germany. Surface soil moisture $(0-6 \mathrm{~cm})$ was measured in an approx. $50 \times 50 \mathrm{~m}$ grid during 14 and 17 measurement campaigns (May 2007 to November 2008) in both test sites. To analyse the spatio-temporal patterns of surface soil moisture, an Empirical Orthogonal Function (EOF) analysis was applied and the results were correlated with parameters derived from topography, soil, vegetation and land management to link the patterns to related factors and processes. For the grassland test site, the analysis resulted in one significant spatial structure (first EOF), which explained 57.5\% of the spatial variability connected to soil properties and topography. The statistical weight of the first spatial EOF is stronger on wet days. The highest temporal variability can be found in locations with a high percentage of soil organic carbon (SOC). For the arable test site, the analysis resulted in two significant spatial structures, the first EOF, which explained $38.4 \%$ of the spatial variability, and showed a highly significant correlation to soil properties, namely soil texture and soil stone content. The second EOF, which explained $28.3 \%$ of the spatial variability, is linked to differences in land management. The soil moisture in the arable test site varied more strongly during dry and wet periods at locations
\end{abstract}

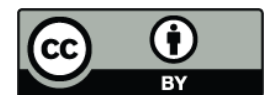

Correspondence to: W. Korres (wolfgang.korres@uni-koeln.de) with low porosity. The method applied is capable of identifying the dominant parameters controlling spatio-temporal patterns of surface soil moisture without being affected by single random processes, even in intensively managed agricultural areas.

\section{Introduction}

Soil moisture is one of the fundamental variables in hydrology, meteorology and agriculture as it plays a major role in partitioning energy, water and matter fluxes at the boundary between the atmosphere and the pedosphere. Its spatiotemporal distribution influences the partitioning of precipitation into infiltration and runoff (Western et al., 1999a) and it partitions the incoming radiation into latent and sensible heat due to the control of evaporation and transpiration. It has a strong impact on the response of stream discharge to rainfall events, it plays a significant role in producing floods (Kitanidis and Bras, 1980) and affects erosion from overland flow and the generation of gullies (Moore et al., 1988). More discharge and erosion have been observed in areas with high soil moisture that are well connected to channels (Ntelekos et al., 2006). The spatio-temporal variation of soil moisture is also reflected in spatial patterns of plant growth and crop yield (Jaynes et al., 2003). For example, crop yield is highly sensitive to early season soil moisture conditions, especially during seed germination (Green and Erskine, 2004).

Due to difficulties in measuring spatio-temporal patterns of soil moisture at larger scales and owing to the importance of these patterns for many environmental processes, great efforts were undertaken to derive spatially distributed soil moisture maps from remote sensing and modelling (Oppelt et al., 1998; Owe and Van de Griend, 1998; Schneider,

Published by Copernicus Publications on behalf of the European Geosciences Union. 
2003). Since surface soil moisture data is potentially available for large areas using remote sensing products (Koyama et al., 2010), it is of great interest to analyse the driving parameters which explain these patterns. To build an adequate model, all relevant processes that affect spatial and temporal soil moisture variability must be identified and addressed. In case of strong spatial variations in soil properties or a dominance of vertical fluxes, such as evapotranspiration or infiltration, soil moisture patterns are controlled by local properties and processes (Grayson et al., 1997; Vachaud et al., 1985). If soil moisture is horizontally redistributed by lateral fluxes, non-local dependencies can play a decisive role (Herbst and Diekkrüger, 2003). Both, locally and non-locally controlled processes and their varying importance in time are essential for the determination of soil moisture patterns. Hawley (1983) determined that topography (relative elevation) is the most important driver of soil moisture in small agricultural watersheds. Even in watersheds with little slope, soil moisture values are consistently higher at the bottom of the slope. Vegetation tends to override this topographic influence. The effect of soil texture on surface soil moisture appears to be larger under wet conditions; minor variations in soil type seem to be insignificant. For all soil texture classes (except sands), soil moisture variability is typically high in a mid range between 18 and 23 Vol.-\% (Vereecken et al., 2007). On a 1.4 ha hillslope, Burt and Butcher (1985) detected the development of saturated areas in downhill, low slope and convergent locations, indicating lateral redistribution of soil water via saturated flow above impermeable bedrock. The correlation between Wetness Index (WI; Beven and Kirkby, 1979) and soil moisture was generally better during wet conditions (Burt and Butcher, 1985). However, lateral water movement in unsaturated soils can also be observed and may reach the same order of magnitude as the vertical movement. This is caused by anisotropic permeability due to different soil layers (Zaslavsky and Sinai, 1981; Herbst et al., 2006). For the Tarrawarra grassland catchment in south eastern Australia (Western et al., 1999a), the highest correlation between soil moisture and topographic characteristics occurred for moderately wet conditions. This relationship deteriorates for dry and very wet (near saturation) conditions. The soil moisture autocorrelation calculated for different dates generally showed longer correlation length on dry dates, related to the larger spatial scale of evapotranspiration as the dominant driver. The shorter correlation length on wet days seems to be connected to the smaller spatial scale of lateral redistribution (Western et al., 1998). Green and Erskine (2004) found no clear correlation length of soil moisture at the field scale for a semi-arid climate. Western et al. (2004) compared soil moisture correlation lengths with the spatial correlation of terrain attributes indicating the important role of topography at one site and the variation of soil properties at other sites. Empirical Orthogonal Function (EOF) analysis can be used to identify the dominant processes and essential parameters controlling soil moisture patterns. Since introduced to the analysis of geophysical fields by Lorenz (1956), EOF analysis has been widely applied for the analysis of the spatial and temporal variability of large multidimensional datasets and has been commonly used in meteorological studies. More recently it has also been used to analyse soil moisture patterns at a large variety of scales, from the field scale for agricultural sites (Yoo and Kim, 2004), to catchment scales (Perry and Niemann, 2007), and to regional scales (Jawson and Niemann, 2007; Kim and Barros, 2002). The result of this analysis is a small number of spatial structures (EOFs) that explain a high percentage of variation of the dataset and temporal varying coefficients (ECs), which modulate the influence of these spatial structures in time. Utilizing correlation analyses, these underlying (stable) patterns of soil moisture variations can be connected to parameters derived from topography, soil, vegetation, land management and meteorology. Our dataset contains "snapshots" in time and the intention of our analysis is not to analyse continuous soil moisture seasonality. The main objectives of this study are to identify the dominant parameters and underlying processes controlling the stable spatial and temporal patterns of surface soil moisture under different soil moisture states and to examine whether the application of this method in agriculturally used areas, which are affected by heterogeneous, land-use dependent management procedures, also provides reasonable results.

\section{Test sites}

Field measurements were carried out in a grassland test site in Rollesbroich and an arable test site in Selhausen, both located west of Cologne, Germany. The grassland site $\left(50^{\circ} 37^{\prime} 25^{\prime \prime} \mathrm{N} / 6^{\circ} 18^{\prime} 16^{\prime \prime} \mathrm{E}\right)$ covers an area of approximately 20 ha with nine fields of extensively used grassland (Fig. 1). This test site is typical for the low mountain ranges of the Eifel. Slopes range from 0 to $10^{\circ}$, while altitude ranges from 474 to $518 \mathrm{~m}$ a.s.l. Mean annual air temperature and average annual precipitation measured at a meteorological station $9 \mathrm{~km}$ west (altitude $505 \mathrm{~m}$ ) of the test site are $7.7^{\circ} \mathrm{C}$ and $1033 \mathrm{~mm}$, respectively. No pronounced seasonality in precipitation can be found. The dominant soils are (gleyic) Cambisol, Stagnosol and Cambisol-Stagnosol. The grassland vegetation is dominated by a ryegrass society, particularly perennial ryegrass (Lolium perenne) and smooth meadow grass (Poa pratensis).

The arable site $\left(50^{\circ} 52^{\prime} 10^{\prime \prime} \mathrm{N} / 6^{\circ} 27^{\prime} 4^{\prime \prime} \mathrm{E}\right)$ covers an area of approximately 34.3 ha and represents an intensively used agricultural area, where crops are grown on gentle slopes $(0$ $\left.4^{\circ}\right)$. The altitude ranges from 102 to $110 \mathrm{~m}$ a.s.l. A mean annual air temperature of $9.8^{\circ} \mathrm{C}$ and an average precipitation of $690 \mathrm{~mm}$ with slightly higher values occurring in June and July were measured at a meteorological station $4.5 \mathrm{~km}$ to the north-west (altitude $90 \mathrm{~m}$ ). Main soils are (gleyic) Cambisol and (gleyic) Luvisol with a high amount of coarse alluvial 


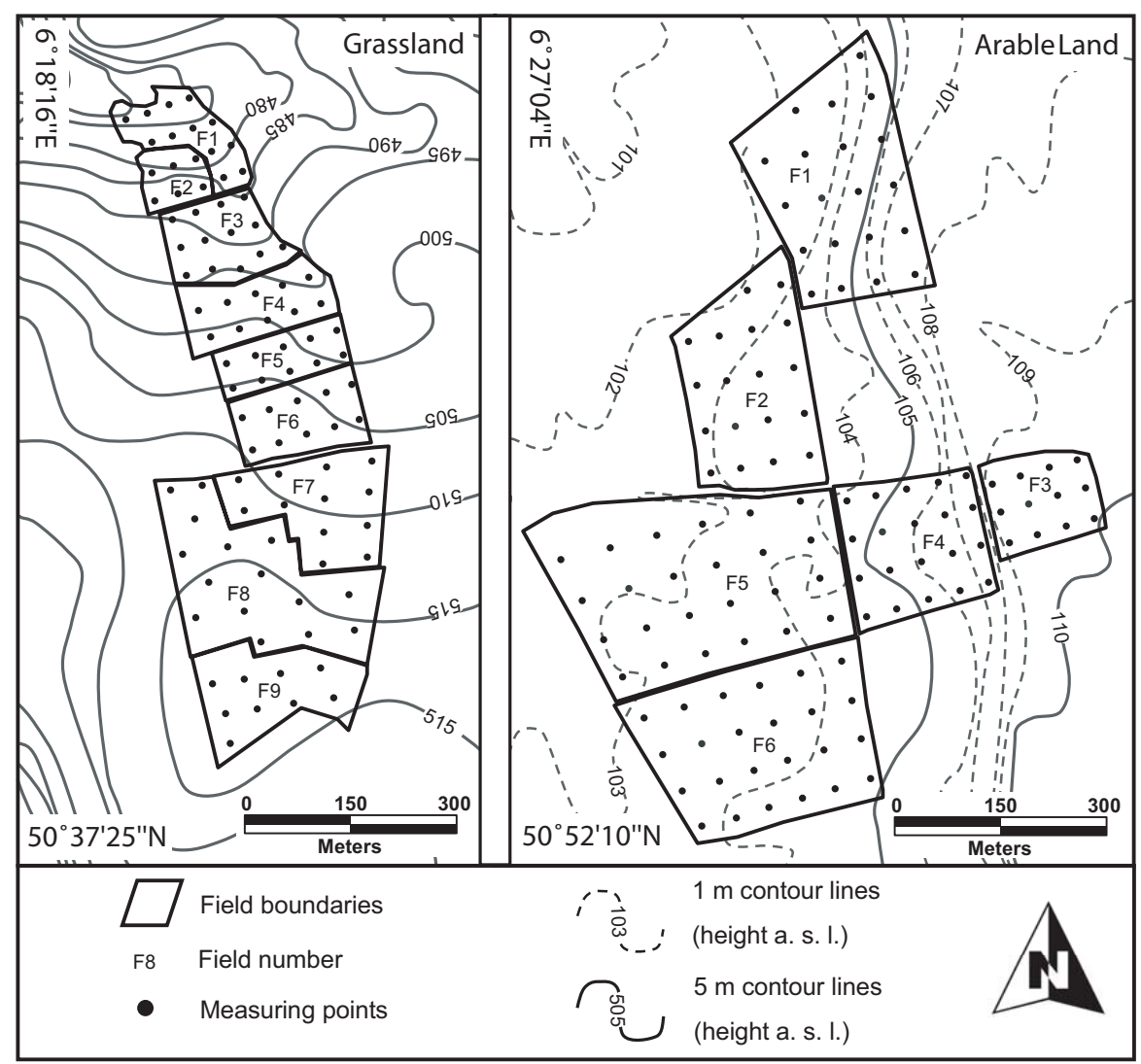

Fig. 1. Topography, field layout and measuring grid of the grassland (Rollesbroich) and the arable test site (Selhausen).

deposits on a former river terrace in the eastern part. The land cover types during the measurement period were sugar beet (beta vulgaris), wheat (triticum aestivum), rye (secale cereale), oilseed radish (raphanus sativus oleiformes) and fallow.

\section{Field measurements}

\subsection{Grassland test site}

Surface soil moisture measurements for the topsoil layer (0$6 \mathrm{~cm}$ ) were performed on an approx. $50 \times 50 \mathrm{~m}$ grid (Fig. 1). The measurement locations were slightly adjusted according to local conditions such as field boundaries. While the average distance to the next measurement location was $50 \mathrm{~m}$, the minimum distance was $20 \mathrm{~m}$ and ranged up to $60 \mathrm{~m}$. Measurements were taken during 14 campaigns from May 2007 to November 2008 at 41 to 96 locations. To provide representative values, each measurement location is represented by the average of six measurements carried out within a radius of $10 \mathrm{~cm}$. Soil moisture was measured with handheld FDR probes (Delta-T Devices Ltd., Cambridge, UK). The probes were calibrated individually in the laboratory using a mixture of water and glass beads to provide well defined water content and tested on soil samples from the test sites. Based on these lab procedures, the FDR probes yield an absolute accuracy of \pm 3 Vol.- $\%$ and a relative accuracy of \pm 1 Vol.- $\%$ (Delta-T Devices Ltd., Cambridge, UK). To investigate the influence of soil texture and soil organic carbon (SOC) on the surface soil moisture, soil samples in three depths $(0-10 \mathrm{~cm}$, $10-30 \mathrm{~cm}$ and $30-60 \mathrm{~cm}$ ) were taken at every sampling location. Carbon content and soil texture were determined using mid-infrared-spectroscopy (Bornemann et al., 2008). The results from spectroscopy analysis were calibrated to carbon content using samples analysed with a CN Elementar Analysator (Elementar, Germany). In addition, topsoil $(0-5 \mathrm{~cm})$ porosity and soil organic matter $(\mathrm{SOM})$ were measured at four locations in the northern part of the test site, where very high surface soil moisture values (up to 75 Vol.$\%$ ) were determined (especially field F2).

\subsection{Arable test site}

Similarly to the grassland test site, surface soil moisture $(<6 \mathrm{~cm})$ was measured in the arable test site on a grid of approx. $50 \times 50 \mathrm{~m}$ (Fig. 1). Again the locations were adjusted according to local conditions and field boundaries. Measurements were taken during 17 campaigns between May 2007 and November 2008 at 44 to 118 locations. Soil information 
was taken from a high resolution soil map (Bodenkarte 1:50 000, Geologischer Dienst, North-Rhine-Westphalia). A terrace slope with an elevation difference of about 2-3 m cuts through the test site. Soil translocation by tillage operations at the edge of the terrace result in a high percentage of stones at the surface in the vicinity of the terrace slope. The upper terrace plain has a high stone content, while the lower plain generally shows a lower stone content. The stone cover on the surface within a sample area of $0.4 \times 0.4 \mathrm{~m}$ was visually estimated at each measuring location using a wooden frame. On every location, three replicate measurements were taken. Using previously measured data of the course fraction of soil material, a relationship between the stone cover and the coarse fraction of the top soil layer $(0-30 \mathrm{~cm})$ was established by correlation analysis for two parallel transects with 8 measurement points. This analysis resulted in a Pearson correlation coefficient of $r=0.89$. The stone cover analysis is subsequently used in the pattern analysis. The ground based data set was complemented by data on the tillage practice for each field.

\section{Methods}

\subsection{Empirical Orthogonal Functions analysis}

Empirical Orthogonal Functions (EOF) analysis is one of the best known data analysis techniques and a well established method of multivariate data analysis (Jolliffe, 2002). The EOF analysis, also known as principal component analysis, decomposes the observed variability of a dataset into a set of orthogonal spatial patterns (EOFs) and a set of time series called expansion coefficients (ECs). While single soil moisture patterns might be affected by random processes (e.g. rainfall shortly before measuring), significant EOFs represent stable patterns of a dataset and are by definition not random (definition of statistical significance in Sect. 4.2). The existing degree of randomness of a single soil moisture pattern is reflected by the associated EC, since the EC value represents the proportion of the significant EOF pattern in the soil moisture pattern of each date. In consequence, we did not use single soil moisture patterns (which might be random) but the EOF patterns for the subsequent correlation analysis.

Measurements, taken at location $x_{i}(i=1, \ldots p)$ and at time $t_{j}(j=1, \ldots n)$, are arranged into a matrix $\mathbf{D}(n$ by $p: n$ sampling times and $p$ sampling locations), in a so called S-mode. Each row of the matrix represents the measurements at one point in time at all locations and each column represents a time series of measurements for a given location. To analyse the spatial variability of the data, a matrix $\mathbf{F}$ is computed from the matrix $\mathbf{D}$ by subtracting the average of each row of the data matrix $\mathbf{D}$ (average soil moisture for a given observation time over all measurements locations). Analogously, to analyse the temporal variability, the average of each column is subtracted from matrix $\mathbf{D}$ (average soil moisture for a given location for all measurements conducted at that location). In the next step, the covariance matrix $\mathbf{R}$ ( $p$ by $p$ ) of the data matrix $\mathbf{F}$ is calculated:

$\mathbf{R}=\frac{1}{N-1} \mathbf{F}^{t} \mathbf{F}$

where the superscript $t$ indicates a transposed matrix and $N$ is the number of observations.

$\mathbf{R}$ is diagonalized to find the eigenvectors and eigenvalues:

$\mathbf{R C}=\mathbf{C} \Lambda$

where $\Lambda$ ( $p$ by $p$ ) is a diagonal matrix containing the eigenvalues $\lambda_{i}$ of $\mathbf{R}$, and $\mathbf{C}$ ( $p$ by $p$ ) contains the eigenvectors $\boldsymbol{c}_{i}$ of $\mathbf{R}$ in the column vectors, corresponding to the eigenvalues $\lambda_{i}$. For more details on the procedure see Jolliffe (2002); Hannachi (2007) or Preisendorfer (1988).

This procedure rotates the original coordinate axes in a multidimensional space to align the data along a new set of orthogonal axes in the direction of the largest variance. Thus, the first axis or eigenvector is oriented in the direction that explains the largest variance. The subsequent axes are constrained to be orthogonal to the axes computed before and consecutively explain the largest part due to the remaining covariance. The eigenvectors $\boldsymbol{c}_{i}$ in the columns of the matrix $\mathbf{C}$ are the EOFs. The EOFs represent patterns or standing oscillations that are invariant in time. To analyse how the EOFs evolve in time, the expansion coefficients (ECs) associated with each EOF are calculated by projecting the matrix $\mathbf{F}$ onto the matrix $C$ :

$\mathbf{A}=\mathbf{F C}$

where the matrix A contains the expansion coefficients $a_{i}$ in the column vectors.

The EOF analysis produces $p$ ( $p=$ sampling locations) $\mathrm{EOF} / \mathrm{EC}$ pairs, but only min $(n, p)$ eigenvalues $(n=$ sampling times) are greater than zero and only a subset (usually a much smaller set) of these positive eigenvalues are meaningful. In general, the EOFs and ECs are rearranged in descending order due to their eigenvalues, so that the first EOF (EOF1) is associated with the largest eigenvalue. The fraction of variance explained $(E V)$ by each EOF can be found by dividing the associated $\lambda_{i}$ by the sum of all eigenvalues (the trace of $\Lambda)$ :

$E V_{i}=\frac{\lambda_{i}}{\sum_{i=1}^{p} \lambda_{i}}$

Following Björnsson and Venegas (1997) and Hannachi et al. (2007), the EOFs and the ECs can be determined very efficiently by singular value decomposition (SVD) without computing the covariance matrix and solving the eigenvalue problem. This decomposition by SVD provides a compact representation, because it drops unnecessary zero singular values (equivalent to zero eigenvalues). 


\subsection{Selection of significant EOFs}

After decomposition, the EOFs and ECs can be used to reconstruct the full variability of the dataset by selecting all EOF/EC pairs. However, to approximate and compress a dataset, only the first few EOF and EC pairs that explain the largest fraction of variance are usually selected. This results in a reduction of dimensionality. By truncating the system, a "cleaner" version of the dataset is constructed, because random noise contained in the higher order EOFs is eliminated (Björnsson and Venegas, 1997; Preisendorfer, 1988). In practice, this truncation is often achieved by selecting a threshold for the overall explained variance (e.g. 80\%) and choosing the set of leading EOFs that cumulatively explain at least this amount of variance. A prerequisite for the physical interpretation of single EOFs is that the EOFs are significantly different from each other. The linear combination of two EOFs, which are not significantly different and therefore degraded, may be based upon the same underlying physical processes. Thus, any linear combination of patterns based on degraded EOFs is as significant as each one of them (Hannachi et al., 2007).

To estimate the correct number of significant patterns (EOFs) for the subsequent physical interpretation, two selection rules are applied. One rule utilizes a measure of uncertainty for the eigenvalues and is summarized by the rule of thumb (North et al., 1982) defining the typical error $(\Delta)$ of eigenvalues:

$\Delta\left(\lambda_{i}\right) \approx \lambda_{i} \sqrt{\frac{2}{s}}$

where $s$ is the number of independent samples (or the number of degrees of freedom).

The $95 \%$ confidence interval $\left(\mathrm{CI}_{95}\right)$ for each eigenvalue is then given by:

$\mathrm{CI}_{95}\left(\lambda_{i}\right) \approx \lambda_{i}\left(1 \pm \sqrt{\frac{2}{s}}\right)$

The EOFs are considered to be significantly non degenerate if the $95 \%$ confidence intervals of the neighbouring eigenvalues do not overlap.

An additional rule is to use Monte Carlo simulations to estimate the uncertainties of the eigenvalues (Rule N; Preisendorfer, 1988). The eigenvalues of the measured data set have to be significantly higher than the eigenvalues of a random dataset. To test this, one thousand realisations of normally distributed surrogate data sets with a zero mean and a standard deviation of one in the dimension of the matrix of the original dataset ( $n$ by $p$ ) are calculated and analysed by the EOF analysis. From the results of these one thousand realisations, the upper $95 \%$ confidence interval of the eigenvalues is calculated and taken as the limit for the significance of the eigenvalues of the measured dataset. Another calculation with randomized measured values instead of normally distributed surrogate data resulted in the same number of significant EOFs and is not additionally presented here. In this calculation, the positions of the elements of the real measurement data matrix were randomized along one dimension. For the spatial Monte Carlo-analysis, the positions of the elements in every row (all measurements on every single date), for the temporal Monte Carlo-analysis, the positions of the elements in every column (all measurements at every single point) were randomized.

Both selection rules were used in our data analysis to determine the number of significant EOF/EC pairs. Both require knowledge of the number of independent samples $(s)$. In Eq. (6), the number of independent samples was used directly to estimate the errors of the eigenvalues and in the Monte Carlo analysis, the dimensions of the surrogate data matrix were changed from ( $n$ by $p: n$ sampling times and $p$ sampling locations) to ( $n$ by $s$ ) for the spatial and to ( $s$ by $p$ ) for the temporal analysis, resulting in a higher limit for the first few EOFs to be considered significant. This number of independent samples (or degrees of freedom) is calculated in Sect. 5.2.

\subsection{Secondary parameters and correlation analysis}

The aim of the EOF analysis is to identify stable spatial and temporal patterns in a set of surface soil moisture measurements. To identify the dominant drivers governing the surface soil moisture patterns, the EOFs were correlated with secondary parameters derived from topographical, soil, vegetation, land management and meteorological data. The EOFs may only be correlated with parameters that are invariant in time. The temporal development of biomass may explain, to some degree, the soil moisture patterns at a given day due to growth, cutting or grazing for instance, but it does not provide a temporally invariant signal and is therefore not suitable to explain the EOF patterns. Accordingly, it is only useful to correlate the EC time series with parameters which are invariant in space. This condition can be assumed to be valid for the parameter precipitation, because of the small size of our test sites.

The parameters used in our correlation analysis are associated with parameters determining vertical/local (e.g. field capacity, soil texture, SOC etc.) and horizontal/non-local (e.g. elevation, flow accumulation, curvature etc.) water flow. Elevation, multiple flow accumulation (e.g. specific drainage area), natural log of the multiple flow accumulation, slope, slope $^{-1}$, horizontal curvature, vertical curvature and Wetness Index are computed from a $10 \mathrm{~m}$ DEM (Sci Lands, 2008) with ArcGis 9.2 (ESRI, USA). Soil type data in the grassland test site was derived from the 1:5000 soil map (Geologischer Dienst, North-Rhine-Westphalia) and was particularly used to delineate an gleyic area (Stagnosol; impermeable soil layer). Field capacity in the arable test site was derived from the 1:50000 soil map (Geologischer Dienst, North-Rhine-Westphalia). The percent of surface stone cover in the arable test site and the percent clay, silt, sand and SOC 
in the grassland test site were measured. Topographic parameters such as Wetness Index, Flow Accumulation, Slope and Curvature were not computed for the arable test site, since in this predominantly flat area, the flow path is affected by features such as field boundaries and tillage tracks within the field rather than the slope given in the DEM.

\section{Results}

\subsection{Analysis of field measurements}

Both test sites show a large range of different soil moisture conditions (Figs. 2, 3), ranging from very dry conditions (22.2 Vol.-\% in the grassland test site, and 19.5 Vol.$\%$ in the arable test site) to very wet conditions (54.3 Vol.$\%, 32.5$ Vol.- $\%$, respectively). The soil moisture over all measurements generally indicates higher average values (46.5 Vol.-\%) for the grassland site as compared to the arable test site (26.6 Vol.-\%) and a lower spatial variability (coefficient of variance (CV): $9.6 \%$ for grassland, $14.2 \%$ for arable land). The average standard deviation of the soil moisture over all days of measurement in the grassland test site was 4.5 Vol.-\% (Min.: 3.2 Vol.-\%, Max.: 5.8 Vol.-\%, ) and in the arable test site, it was 3.8 Vol.-\% (Min.: 2.3 Vol.-\%, Max.: 6.3 Vol.-\%). Due to the higher soil moisture status in the grassland test site, the range of the average soil moisture in the grassland test site (32.1 Vol.-\%) exceeded the respective range in the arable test site $(13.1 \mathrm{Vol} .-\%)$. These differences are due to the higher precipitation, the higher soil porosity and the higher amount of soil organic carbon content (SOC) in the topsoil of the grassland test site. Extremely high surface soil moisture values were particularly measured in field F2 in the grassland test site, which is located in the lowest part of the test site. Due to the dense root network of the grass cover, the amount of soil organic matter (SOM) in the topsoil is higher than 8 Vol.-\% $\%$. Hence low bulk densities $(0.57$ to $0.83 \mathrm{~g} \mathrm{~cm}^{-3}$ ) prevail, with smallest values measured in the lower northern part of the test site with dominating gleyic soils. Due to the high organic content in this area, the maximum porosity reached values of up to $70 \%$ in the topsoil. In the arable test site, the maximum measured soil moisture reached 40\%. The length of the whiskers in Fig. 2 indicates a large spatial variability of the surface soil moisture in the grassland test site. The average range of the soil moisture values measured in the grassland test site is 25.3 Vol.-\% (Min.: 14.3 Vol.-\%, Max.: 36.1 Vol.-\%) and 18.4 Vol.-\% (Min.: 9.1 Vol.-\%, Max.: 25.9 Vol.-\%) in the arable test site. The measurements of the 14 measurement campaigns in the grassland test site and the 17 in the arable test site accumulate to a total number of 17124 FDR-measurements. To avoid the imputation of missing values and to keep the results interpretable, the EOF analysis was computed with a continuous data set without missing data. Thus only 8 of the 14 measurement days from the grassland test site and 10 of the 17 measuring days from the arable test site were used for the subsequent analysis.

\subsection{Degrees of freedom}

For the evaluation of spatial interdependencies between the measurement locations, a spatial autocorrelation analysis was performed, calculating Moran's I statistic (Moran, 1950) for a number of distance classes. This statistic calculates values between 1 (indicating perfect correlation) and -1 (perfect dispersion) between the different distant classes, a value of 0 indicates a completely random pattern. A number of 25 distance classes, each containing 183 data pairs for each day of measurement, were calculated for the grassland. For the arable test site, 30 classes were computed. Over all measurement campaigns, we determined an average autocorrelation length of $117 \mathrm{~m}$ for the grassland test site and $123 \mathrm{~m}$ for the arable test site. Hence, 16\% (grassland) and 9\% (arable land) of all distance pairs are assumed to be autocorrelated. The number of significant EOFs is sensitive to the number of independent samples (degrees of freedom). Thus, to account for the influence of spatial autocorrelation on the evaluation of significant EOFs, the number of sampling locations was reduced by these percentages of autocorrelated distance pairs, resulting in 81 and 107 independent spatial sampling locations for the grassland test site and the arable test site, respectively. For the temporal analysis, dates of each measurement campaign were considered to be independent, if the time span between two measurement dates added up to at least 20 days. This resulted in 6 and 8 degrees of freedom for the calculation of significance in the time domain.

\subsection{EOF-Analysis}

The analysis of the spatial patterns in the grassland test site yields a set of $8 \mathrm{EOF} / \mathrm{EC}$ pairs. EOFs calculated for analysing spatial patterns are referred to as spatial EOFs. Analogously, EOFs calculated to investigate temporal patterns are referred to as temporal EOFs. The spatial EOF1 of the grassland test site explains $57.5 \%$ of the spatial variance of the dataset, while EOF2 explains only $10.2 \%$ (Fig. 4a). The $95 \%$ confidence limit of the Monte Carlo simulation exceeds the explained variance of EOF2 to EOF8. Also, the 95\% confidence interval of EOF1 does not overlap with the neighbouring EOFs. As a result, the first EOF is significant. The pattern of the spatial EOF1 (Fig. 5a) shows high positive values. This indicates higher than average soil moisture values in the northern part (fields F1, F2 an F3), which is in the valley section of the test site. Highest positive values can be found in field F2. Minimum values with negative signs are located in the central part of the test site (field F6). The EOF values increase slightly towards the southern part. The associated expansion coefficient (spatial EC1, Fig. 5b) shows a maximum value on 29 April 2008 and a minimum value on 


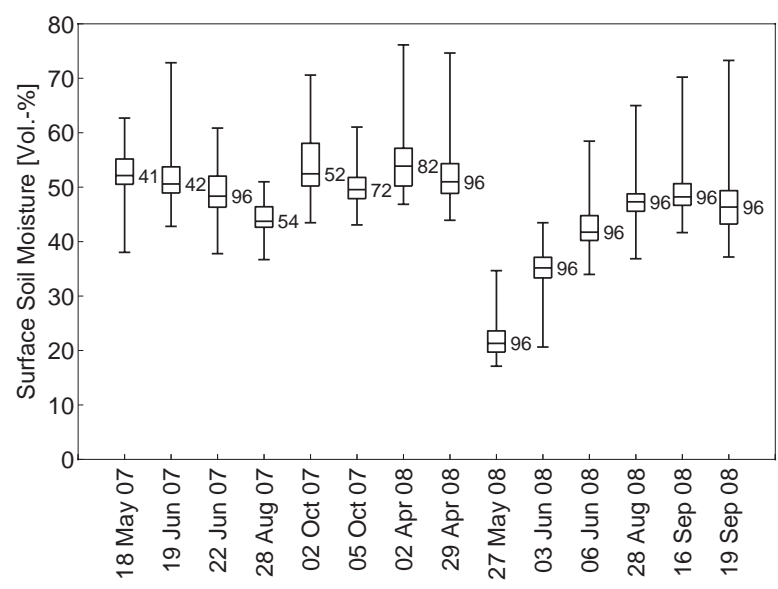

Fig. 2. Box-Whisker-Plot for the grassland site of all days of surface soil moisture measurements; the bottom and top of the box show the lower and upper quartiles, the band near the middle of the box is the median, the ends of the whiskers represent the measured minimum and maximum surface soil moisture; the number to the right of each box indicates the number of sampling locations for each date; data sets without gaps $(n=96)$ were used for the EOF analysis.

3 June 2008. This maximum EC1 values coincides with the high average soil moisture values on these measuring dates, while the low EC values indicate dry conditions.

The analysis of the spatial patterns in the arable test site yields a set of $10 \mathrm{EOF} / \mathrm{EC}$ pairs. The spatial EOF1 explains $38.4 \%$ and EOF2 $28.3 \%$ of the spatial variability of the dataset (Fig. 6a). Only these first two EOFs satisfy the significance requirements, because the $95 \%$ confidence intervals of their eigenvalues neither overlap with neighbouring confidence intervals nor are their eigenvalues within the $95 \%$ confidence interval of the eigenvalues of the Monte Carlo simulation. All eigenvalues and confidence limits can be converted into $E V$-values (see Figs. $4 \mathrm{a}, \mathrm{b}$, and $6 \mathrm{a}, \mathrm{b}$ ) according to Eq. (4). The spatial EOF1 (Fig. 7a) shows the lowest negative values in the eastern part of the test site and an irregular and patchy pattern with higher values in the rest of the test site. The EOF2 (Fig. 7b) shows a two peaked distribution with high positive values on some fields contrasted by low negative values on other fields with an abrupt change of the EOF values typically at the field boundaries. The values of the EC1 (Fig. 7c), which express the weight of the EOF1 on the different dates, are positive on all dates and reach a maximum value on 27 July 2007 and a minimum value on 24 April 2008. The values of the EC2 (Fig. 7d) show a minimum value with a negative sign on 19 September 2008 and a maximum and positive value on 27 July 2007 . Thus, the influence of the EOF1 varies only gradually during the dates of measurements, while the EOF2 reverses its influence in an annual cycle.

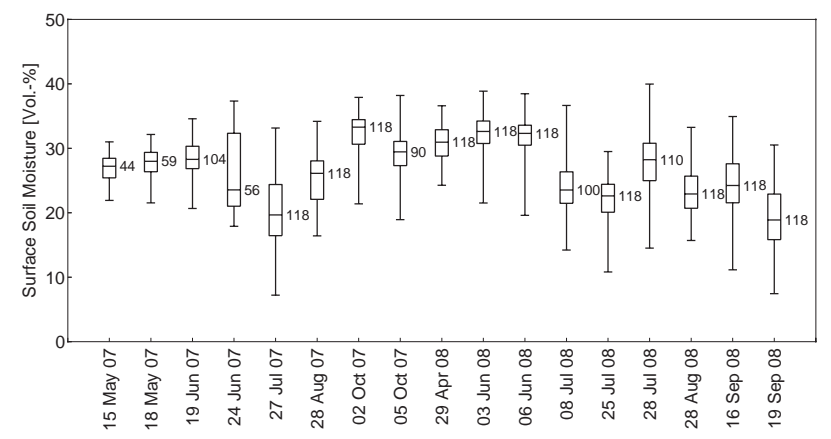

Fig. 3. Box-Whisker-Plot for the arable test site of all dates of measurements; the bottom and top of the box show the lower and upper quartiles, the band near the middle of the box is the median, the ends of the whiskers represent the measured minimum and maximum surface soil moisture; the number to the right of each box indicates the number of sampling locations for each date; data sets without gaps $(n=118)$ were used for the EOF analysis.

Both analyses, for the grassland and the arable test site, resulted in only one significant temporal EOF/EC pair (Figs. $4 \mathrm{~b}$ and $6 \mathrm{~b}$ ). The temporal EOF1 of the grassland test site explains $92 \%$ of the temporal variance and all values are positive. It shows a pattern similar to the spatial EOF1. Smaller and negative values occur in the northern part of the test site. However, the pattern is more irregular and patchy (Fig. 8a) as compared to the spatial EOF. The temporal EC1 has a maximum value on 27 May 2008 and a minimum value on 29 April 2008 (Fig. 8b). The temporal EOF1 of the arable test site explains about $72.5 \%$ of the temporal anomalies of the data set (Fig. 6b) and has all positive values with maximum values in field F3 in the eastern part of the test site (Fig. 9a). The associated EC1 has the highest positive value on 2 October 2007 and the lowest negative value on 10 September 2008 (Fig. 9b).

The interpretation of the results from spatial and temporal EOF analyses requires the consideration of the sign of the EOF values and the sign of the associated EC values, because the soil moisture variability explained by this EOF/EC pair (anomalies) is computed by multiplying EOF and EC.

\subsection{Correlation analysis}

The spatial patterns computed from the EOF analysis were correlated with different parameters for the grassland (Table 1) and the arable test sites (Table 2). These parameters were derived from topography, soil, vegetation and land management data and allow relating the patterns found in the EOF analysis to the driving processes. Only significant correlations of the EOF patterns with the parameters are presented here. The spatial patterns determined for the grassland test site show the highest Pearson correlation coefficient with elevation and the soil property gleyic/non gleyic. By distinguishing between gleyic and non gleyic soils, an ordinal scale 

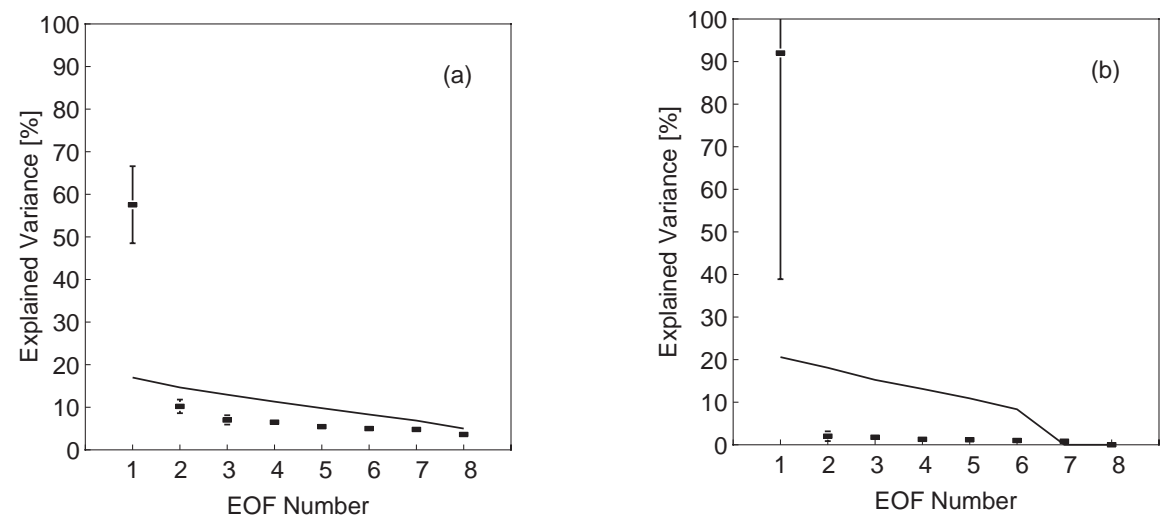

Fig. 4. Variance spectrum of the spatial (a) and temporal (b) analysis in the grassland test site. Error bars indicate the $95 \%$ confidence interval according to Eq. (6); the solid line represents the significance limit calculated by Monte Carlo simulation.

was defined for use in the correlation analysis. The highest correlation for the temporal pattern was with SOC, percentage of sand in the topsoil $(0-10 \mathrm{~cm})$ and soil type. In the arable test site, the first spatial pattern was highly correlated with elevation and soil parameters, particularly the percentage of stone cover and field capacity (Table 2). The correlations of the parameters with the temporal EOF1 pattern were smaller but also highly significant. The second spatial pattern (EOF2) cannot be correlated with any of the tested parameters. The temporal course of the EC1 values of the spatial analysis in both test sites shows a high correlation coefficient with the average soil moisture ( $r=0.73$ for grassland, $r=-0.71$ for arable land). The temporal course of the EC1 patterns for the temporal analysis shows a perfect correlation to the mean soil moisture for both test sites (Table 3). The different signs of the Pearson correlation coefficients are due to the different signs of the EOF values. Several parameters used to explain the EOFs are correlated (e.g. field capacity, \% sand, \% silt and \% clay) and point to the same hydrological process.

\section{Discussion}

\subsection{Spatial analysis}

The analysis performed on the spatial variability in the grassland test site shows that the main soil moisture pattern (spatial EOF1) is strongly related to soil properties and explains about $57.5 \%$ of the spatial soil moisture variation. The highly significant correlations with the soil property gleyic / non gleyic $(r=0.7)$, soil texture (e.g. $\%$ sand $0-10 \mathrm{~cm}: r=-0.42)$, and SOC $(r=0.47$ for $0-10 \mathrm{~cm}$ and $r=0.37$ for $10-30 \mathrm{~cm}$ ) indicate a clear link to infiltration (locally controlled vertical process). The impermeable Stagnosol layer resulted in a higher amount of organic matter and also in a very high porosity in the topsoil at these points. The pattern is also linked to catchment topography. The correlations to pa-
Table 1. Pearson correlation coefficients between EOFs and topographic and soil parameters for the grassland test site; Curvature $\mathrm{H} / \mathrm{V}, \%$ Clay $0-10 \mathrm{~cm}, 10-30 \mathrm{~cm}$ and $\%$ SOC $30-60 \mathrm{~cm}$ were additionally tested but not significant; $E V$ is the variance explained by the EOF

\begin{tabular}{|c|c|c|}
\hline Grassland & $\begin{array}{c}\text { spatial EOF1 } \\
(57.5 \% E V)\end{array}$ & $\begin{array}{c}\text { temporal EOF1 } \\
(92 \% E V)\end{array}$ \\
\hline Elevation [m] & $-0.57(* *)$ & $0.27(* *)$ \\
\hline Flow Accumulation & $0.32(* *)$ & $-0.24(*)$ \\
\hline ln (Flow Accumulation) & $0.45(* *)$ & $-0.23(*)$ \\
\hline Slope $\left[{ }^{\circ}\right]$ & $0.46(* *)$ & not significant \\
\hline 1/Slope $\left[{ }^{\circ}\right]$ & $-0.32(* *)$ & not significant \\
\hline Wetness Index & $0.34(* *)$ & not significant \\
\hline $\begin{array}{l}\text { Soil Parameter gleyic/ } \\
\text { non gleyic }\end{array}$ & $0.70(* *)$ & $-0.34(* *)$ \\
\hline \multicolumn{3}{|l|}{ Sand [\%] } \\
\hline $0-10 \mathrm{~cm}$ & $-0.42(* *)$ & $0.33(* *)$ \\
\hline $10-30 \mathrm{~cm}$ & $-0.4(* *)$ & $0.27(* *)$ \\
\hline $30-60 \mathrm{~cm}$ & $-0.4(* *)$ & $0.26(*)$ \\
\hline \multicolumn{3}{|l|}{ Silt [\%] } \\
\hline $0-10 \mathrm{~cm}$ & $0.41(* *)$ & $-0.30(* *)$ \\
\hline $10-30 \mathrm{~cm}$ & $0.35(* *)$ & $-0.22(*)$ \\
\hline $30-60 \mathrm{~cm}$ & $0.41(* *)$ & $-0.24(*)$ \\
\hline \multicolumn{3}{|l|}{ Clay [\%] } \\
\hline $30-60 \mathrm{~cm}$ & not significant & $0.21(*)$ \\
\hline \multicolumn{3}{|l|}{ SOC $\{\%]$} \\
\hline $0-10 \mathrm{~cm}$ & $0.47(* *)$ & $-0.44(* *)$ \\
\hline $10-30 \mathrm{~cm}$ & $0.37(* *)$ & $-0.25(*)$ \\
\hline
\end{tabular}

* Correlation is significant at the 0.05 level (2-tailed test).

** Correlation is significant at the 0.01 level (2-tailed test).

rameters such as elevation $(r=-0.57)$, natural logarithm of flow accumulation $(r=0.45)$, slope $(r=0.46)$ and Wetness Index $(r=0.34)$ indicate that the spatial pattern is related to landscape position, which is affected by two processes: the 
Table 2. Pearson correlation coefficients between EOFs and topographic and soil parameters for the arable test site; $E V$ is the variance explained by the EOF.

\begin{tabular}{lccr}
\hline Arable land & $\begin{array}{r}\text { spatial EOF1 } \\
(38.4 \% E V)\end{array}$ & $\begin{array}{r}\text { spatial EOF2 } \\
(28.2 \% E V)\end{array}$ & $\begin{array}{r}\text { temporal EOF1 } \\
(72 \% E V)\end{array}$ \\
\hline Elevation [m] & $-0.73(* *)$ & not significant & $0.47(* *)$ \\
Surface stone cover [\%] & $-0.79(* *)$ & not significant & $0.48(* *)$ \\
Field capacity [\%] & $0.75(* *)$ & not significant & $-0.41(* *)$ \\
\hline
\end{tabular}

** Correlation is significant at the 0.01 level (2-tailed test)

position within the landscape determines (i) the redistribution of water through surface runoff and subsurface drainage and (ii) the amount of solar radiation received at this position, which affects the amount of evapotranspiration.

Perry and Niemann (2007) applied an EOF analysis to the widely studied soil moisture dataset of 459 locations at 13 campaigns from the 10.5 ha Tarrawarra grassland catchment (Western and Grayson, 1998; Western et al., 1998, 2001, 1999a, b). The first EOF in their study explained $55 \%$ of the spatial variability of soil moisture. Similar to our results, a clear dependence on hillslope and valley topography was determined which was most prominent during wet periods. Our EOF analysis yielded one significant spatial EOF explaining $57.5 \%$ of the variance. Due to the smaller size of our dataset, the spatial EOF2 (10\% explained variance) is statistically degenerated, whereas the second EOF in the study done by Perry and Niemann (2007) explained 9\% of the spatial variability and could be related to the exposition (or PSRI; Potential Solar Radiation Index). Yoo and Kim (2004) investigated the characteristics of spatial and temporal variability of soil moisture and the relative roles of various affecting factors with the data of the SGP97 Little Washita field site (Famiglietti et al., 1999). Their first EOF accounted for more than $70 \%$ of the variability for interstorm periods and more than $60 \%$ for the whole dataset. The most important factors are topography related to a decreasing role after rainfall stops and an increasing role of soil- and land-use-related factors. Jawson and Niemann (2007) decomposed remotely sensed soil moisture data from the SGP97 field campaign with an EOF analysis and found a single pattern explaining $61 \%$ of the observed spatial variability. The physical characteristic most related to the EOF pattern seemed to be soil texture (percent sand and percent clay). In contrast to the findings of Yoo and Kim (2004), topographic characteristics were relatively unimportant and even less relevant for dry conditions. Jawson and Niemann (2007) attributed this to the fact that topographic characteristics may influence soil moisture patterns mainly through lateral flow. However, lateral flow was not observed at the scale of this study.

In summary it can be stated that our findings are in agreement with the previously mentioned studies that about 55\% to $70 \%$ of surface soil moisture variability can be explained
Table 3. Pearson correlation coefficients between ECs and the soil moisture average from each measuring campaign.

\begin{tabular}{lr}
\hline & $\begin{array}{r}\text { Soil Moisture } \\
\text { Average [\%] }\end{array}$ \\
\hline Grassland spatial EC1 & $0.73(* *)$ \\
Grassland temporal EC1 & $-1.00(* *)$ \\
Arable land spatial EC1 & $-0.71(* *)$ \\
Arable land spatial EC2 & not significant \\
Arable land temporal EC1 & $1.00(* *)$ \\
\hline
\end{tabular}

**Correlation is significant at the 0.01 level (2-tailed test).

by stable patterns and is correlated to soil parameters and topography. On the other hand, our result for the grassland test site indicates that $42.5 \%$ of the spatial variability changes in time and can therefore not be explained by a stable spatial pattern. This portion of the overall variance is mainly due to differences in management (grazing, cutting and fertilizing) of the different fields. Also random noise due to measurement errors contributed to the unexplained variance. In the EOF analysis of spatial patterns, the impact of temporally variable factors, which do not affect the whole area uniformly, results in noise, decreases the amount of the variance explained by the significant EOFs or decreases the number of significant EOFs. In addition, a difficulty in interpreting the results for the grassland test site is the not exactly known location and functionality of old drainage pipes in field F6. While the low values of field F6 might indicate that the drainage tiles are still functioning, a clear relationship with this effect cannot be established. The existence of functioning drainage tiles should yield a stable spatial pattern.

The spatial EC1 is positively correlated with the average soil moisture of the measuring days, meaning that EOF1 reflects more the structure of soil moisture during wet days than during dry days. As expected, during wet periods, lateral redistribution of water over longer distances is possible and the effect of the impermeable soil layer of the soil type (Stagnosol) on surface soil moisture is more pronounced. This leads, in combination with the higher amount of organic 
matter and higher porosity in the topsoil of the Stagnosol area of the test site, to very high topsoil moisture values (up to 75 Vol.-\%). The impact of the Stagnosols decreases as the soil dries with increasing evapotranspiration. Prior findings of Perry and Niemann (2007), indicating a pronounced decrease of the weight of the spatial EOF1 pattern on very dry and very wet conditions, cannot be confirmed by our dataset. Potential causes of this discrepancy might be stronger seasonality in the Tarrawarra catchment and the lack of dry conditions during the measurements in our grassland test site. Also, the first EOF in the Tarrawarra test site is primarily related to landscape position and the associated lateral redistribution of water and subordinately to evapotranspiration, while our first EOF is rather related to soil properties than landscape position.

Most of the previous studies at a comparable spatial scale to our study focussed on test sites with little management impacts. Our study also investigated spatial anomalies in an arable test site. Our results show, that the first spatial EOF in the arable test site is still related to soil properties, namely surface stone cover $(r=-0.79)$ and field capacity $(r=0.75)$ and explains $38.4 \%$ of the variance. However, the second EOF indicates effects originating from different seasonality in tillage operations of the different fields. The spatial patterns of the first EOF can be explained from the effects of an old river terrace which crops out in the eastern part of the test site approximately at an elevation of $107 \mathrm{~m}$ (see Fig. 1) and causes a high amount of coarse alluvial deposits in the adjacent fields (F1/3/4), especially on field F3. Both parameters, stone cover and field capacity, point at the importance of spatial differences of soil properties in relation to soil moisture dynamics. The highly significant correlation with elevation $(r=-0.73)$ must be seen as an artefact from the cross correlation of the presence of outcrop of the old river terrace and its position in the elevation gradient. The correlation between the spatial EC1 and the average soil moisture $(r=0.71)$ shows that the influence of the EOF1 pattern associated with soil properties is more pronounced on dry dates. Due to the lower porosity in the eastern part of the test site, soil moisture decreases more rapidly after precipitation.

The spatial EOF2 shows no significant correlation with any of the tested parameters. However, the variation of the spatial EOF2 values is quite small within the individual fields (coefficient of variation (CV) between -5.2 and $0.6 \%$ ) while it is pronounced between different fields (CV: $-43.5 \%$ ), which indicates that the EOF2 pattern is dominated by a different seasonality in tillage operations in different fields. The importance of tillage operations on soil moisture can be shown for soil moisture dates with similar patterns to the spatial EOF2 values (27 July 2007 between the adjacent fields F5 and F6; 19 September 2008 between the adjacent fields F1 and F2). On both dates, the wetter field of the two was harvested while the drier field was also ploughed the week before the measurements. Because of the higher porosity after ploughing, soil moisture decreased in-
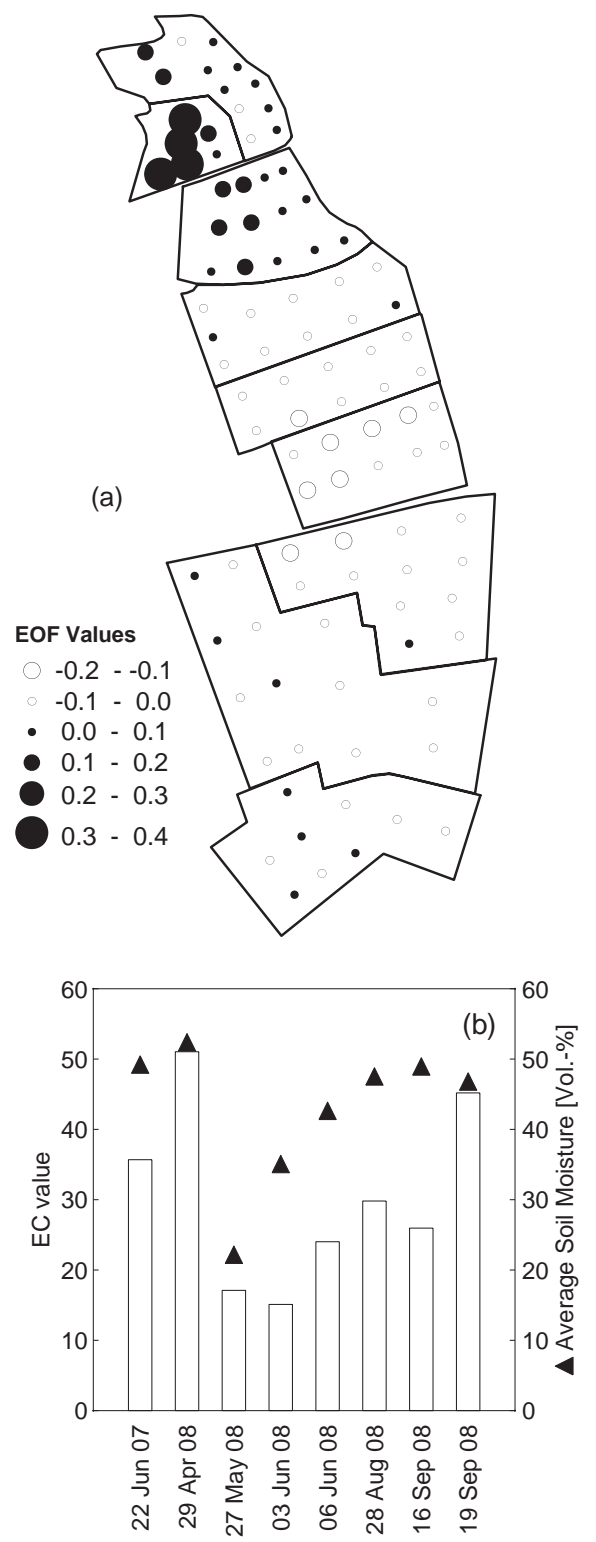

Fig. 5. EOF1 (a) and EC1 (b) patterns of the spatial analysis in the grassland test site; the triangles in (b) represent the average soil moisture on the different days.

ducing a steep gradient at the field boundaries. The highest positive and negative values of the spatial EC2 can be found on days with low average soil moisture, when some field were ploughed just before the measurements (27 July 2007, 16 September 2008 and 19 September 2008). Due to multiple vegetation periods being covered in our multi-annual dataset, there is no spatial stability with regards to land management effects. This is reflected in the negative and positive values of the spatial EC2 in our measurements, indicating a reversing management pattern. Thus, we can identify the influence of the land management by tillage (i.e. the increase of pore volume after ploughing and differences in evaporation) 

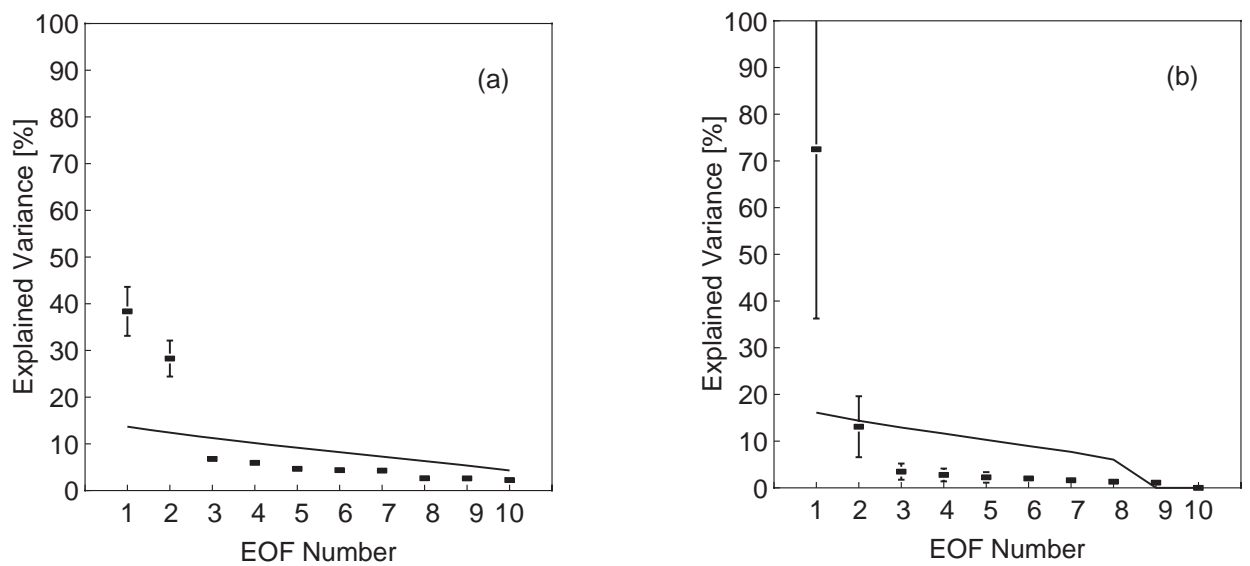

Fig. 6. Variance spectrum of the spatial (a) and temporal (b) analysis in the arable test site. Error bars indicate the $95 \%$ confidence interval according to Eq. (6); the solid line represents the significance limit calculated by Monte Carlo simulation.
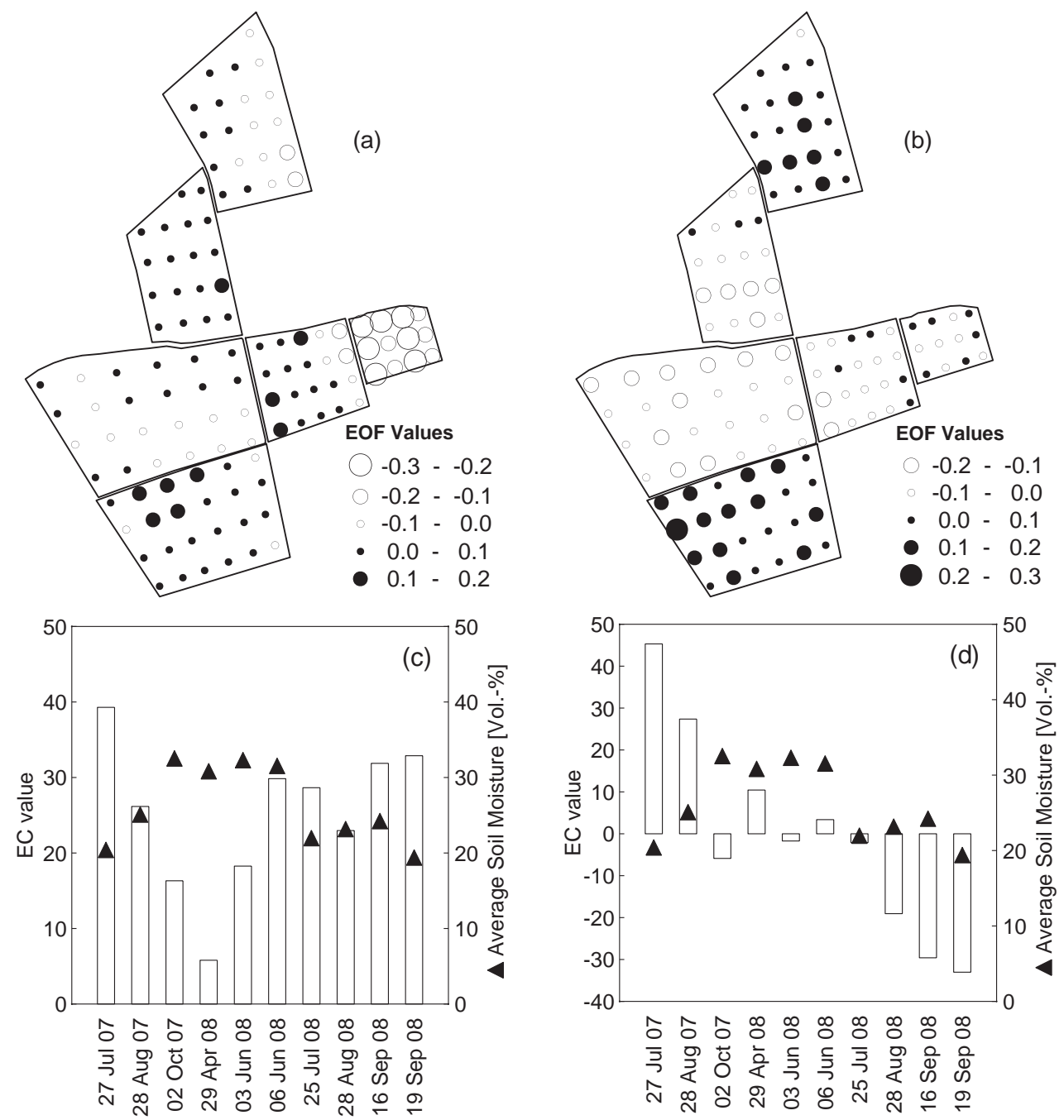

Fig. 7. EOF1 (a), EOF2 (b), EC1 (c) and EC2 (d) patterns of the spatial analysis in the arable test site; the triangles in (c) and (d) represent the average soil moisture on the different days. 
and different crop rotation or vegetation heights, resulting in differences of transpiration. These results from the spatial analysis show that it is possible to apply EOF analyses on managed agricultural fields or regions. The structure of our dataset with alternating management patterns in the two consecutive years of measurements allows to detect not only the stable pattern (connected with soil parameters), but also the non stable pattern of different land management options on the different fields.

\subsection{Temporal analysis}

The temporal analysis identifies locations with large temporal variability. These locations are identified by high absolute numbers in Fig. 8a. Both temporal EC1s have a perfect correlation with the average soil moisture on the days of the measurements, substantiating the control of these patterns by wet and dry periods. The existence of only one dominant mode of temporal variability in each test site, with all negative EOF1 values in the grassland test site and all positive EOF1 values in the arable test site, indicates a consistent reaction of the soil moisture values on dry and wet periods in the same direction on each test site. Both test sites are small enough to assume homogeneous precipitation across the fields over the time of measurements. The comparatively high value of explained variance $(13.1 \%)$ of the temporal EOF2 in the arable test site might indicate the influence of land management. The temporal EOF1 in the grassland test site explains $92 \%$ of the temporal variance. This is related to soil properties (e.g. \% SOC: $r=-0.44$; Soil Type: $r=-0.34$; $\%$ Sand: $r=0.33$ ) and catchment topography (e.g. Elevation: $r=0.27$ ). Therefore, the highest soil moisture variability during dry and wet periods in the grassland test site is located in its low-lying parts. Here also high SOC contents in the topsoil can be found. These high topsoil SOC contents are associated with areas where higher soil moisture content prevails over longer time periods resulting from and indicated by the Stagnosols. In the arable test site, the points with the highest temporal EOF1 values are correlated with surface stone cover $(r=0.48)$ and field capacity $(r=-0.41)$, implying that soil moisture varies more on locations with low porosity. At these locations higher thermal conductivity and lower water holding capacity, caused by higher content of the coarse fraction in the soil, lead to a higher temporal variance of soil moisture.

\section{Conclusions}

Empirical Orthogonal Function analysis was used to detect the stable spatial and temporal patterns of surface soil moisture. A subsequent correlation analysis was used to identify the dominant parameters and underlying processes controlling the stable (significant) spatial and temporal patterns of surface soil moisture under different soil moisture states. In

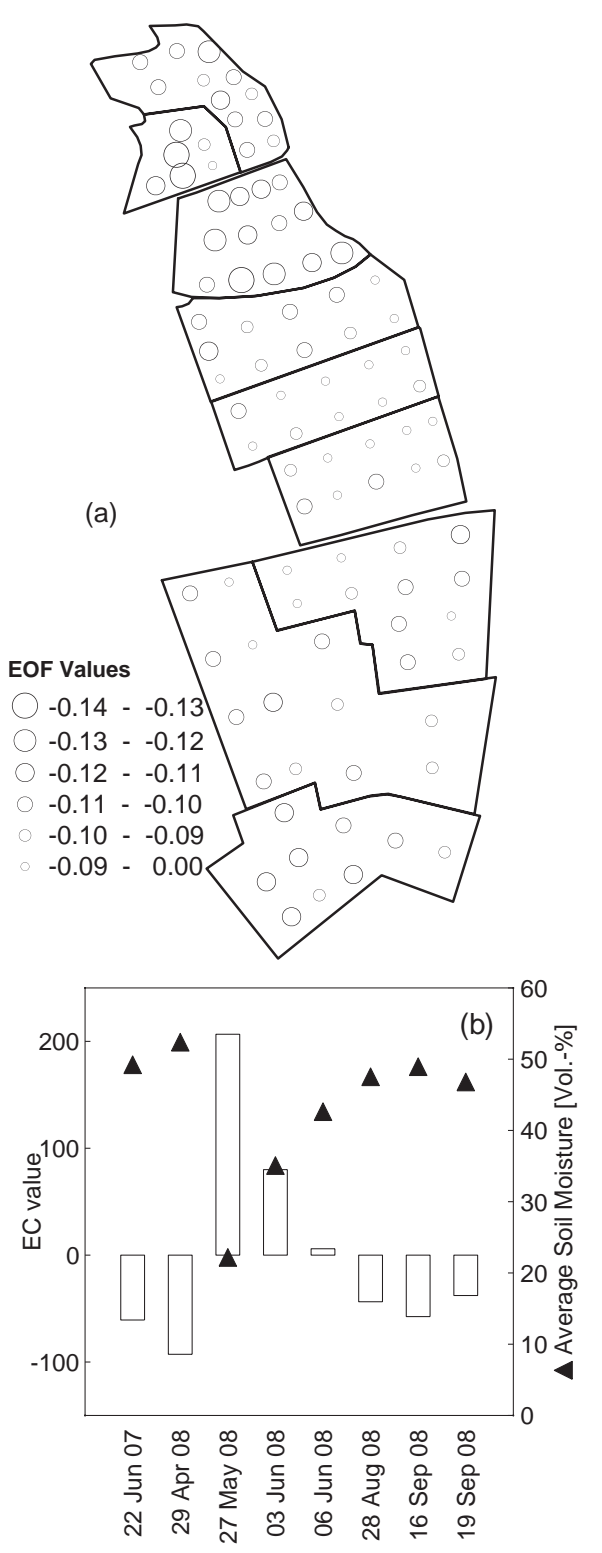

Fig. 8. EOF1 (a) and EC1 (b) patterns of the temporal analysis in the grassland test site; the triangles in (b) represent the average soil moisture on the different days.

the grassland test site (Rollesbroich), one significant spatial pattern, explaining $57.5 \%$ of the spatial soil moisture variability, was determined. This pattern is related to soil properties (soil type) and topography. Its dominance is largest during or shortly after wet periods, because under wet conditions, the lateral redistribution of water and the varying infiltration by different soil types becomes more important. Another significant spatial pattern accounting for the differences in land management (grazing, cutting, fertilizing) could not be identified for the grassland site. The highest soil moisture variability was in the lower parts of the test site at locations with a high percentage of SOC and influenced by the soil 

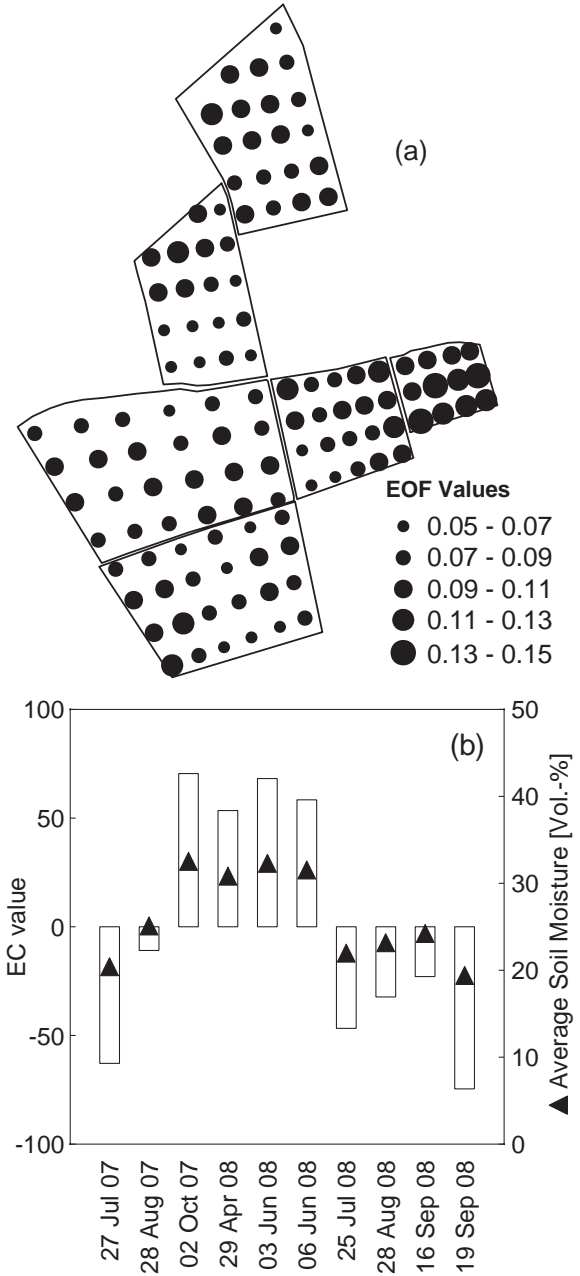

Fig. 9. EOF1 (a) and EC1 (b) patterns of the temporal analysis in the arable test site; the triangles in (b) represent the average soil moisture on the different days.

type in that area. In the arable test site (Selhausen), two significant patterns controlling the major part of the spatial variability were determined. The first pattern (spatial EOF1), accounting for $38.4 \%$ of the variance, is strongly related to soil properties (surface stone cover and field capacity). The impact of this pattern is more pronounced during dry periods, indicating a compensating effect of precipitation. The second pattern (spatial EOF2) explains $28.3 \%$ of the variance and can be assigned to different land management patterns, influencing soil properties and increased evaporation due to tillage as well as transpiration, due to different crops and different dates of sowing and fertilization. More than $66 \%$ of the spatial variability of surface soil moisture in the arable test site can be explained by these two patterns associated with soil properties and land management. The highest temporal variability of soil moisture during the dry and wet periods can be found on locations with low porosity. The struc- ture of our dataset with alternating management patterns in the arable test site in two consecutive years of measurements allows detecting not only the stable pattern (connected with soil parameters), but also the non stable pattern of different land management options on different fields.

In general, a combination of EOF and correlation analysis provides an objective method to identify the dominant parameters controlling spatio-temporal patterns of surface soil moisture, without being affected by single random processes. This is even possible in intensively managed agricultural areas. Moreover, this combination has the capability to quantify the proportion of influence of different parameters on soil moisture patterns under different soil moisture states.

Acknowledgements. We gratefully acknowledge financial support by the SFB/TR 32 "Pattern in Soil-Vegetation-Atmosphere Systems. Monitoring, Modelling, and Data Assimilation" funded by the Deutsche Forschungsgemeinschaft (DFG). We thank L. Bornemann from the Institute of Crop Science and Resource Conservation in Bonn for the soil analysis using mid-infrared-spectroscopy. Special thanks also go to our students for helping with the field measurements and to the farmers in Selhausen and Rollesbroich for granting access to their fields. The authors thank the editor and the four anonymous referees for their helpful comments.

Edited by: N. Verhoest

\section{References}

Beven, K. J. and Kirkby, M. J.: A physically based, variable contributing area model of basin hydrology, Hydrological Sciences Bulletin, 24, 43-69, 1979.

Björnsson, H. and Venegas, S. A.: A manual for EOF and SVD analyses of climate data, McGill University, Montreal, 52 pp., 1997.

Bornemann, L., Welp, G., Brodowski, S., Rodionov, A., and Amelung, W.: Rapid assessment of black carbon in soil organic matter using mid-infrared spectroscopy, Org. Geochem., 39, 1537-1544, 2008.

Burt, T. P. and Butcher, D. P.: Topographic Controls of SoilMoisture Distributions, J. Soil. Sci., 36, 469-486, 1985.

Famiglietti, J. S., Devereaux, J. A., Laymon, C. A., Tsegaye, T., Houser, P. R., Jackson, T. J., Graham, S. T., Rodell, M., and van Oevelen, P. J.: Ground-based investigation of soil moisture variability within remote sensing footprints during the Southern Great Plains 1997 (SGP97) Hydrology Experiment, Water Resour. Res., 35, 1839-1851, 1999.

Grayson, R. B., Western, A. W., Chiew, F. H. S., and Blöschl, G.: Preferred states in spatial soil moisture patterns: Local and nonlocal controls, Water Resour. Res., 33, 2897-2908, 1997.

Green, T. R. and Erskine, R. H.: Measurement, scaling, and topographic analyses of spatial crop yield and soil water content, Hydrol. Process., 18, 1447-1465, 2004.

Hannachi, A., Jolliffe, I. T., and Stephenson, D. B.: Empirical orthogonal functions and related techniques in atmospheric science: A review, Int. J. Climatol., 27, 1119-1152, 2007. 
Hawley, M. E., Jackson, T. J., and McCuen, R. H.: Surface SoilMoisture Variation on Small Agricultural Watersheds, J. Hydrol., 62, 179-200, 1983.

Herbst, M. and Diekkrüger, B.: Modelling the spatial variability of soil moisture in a micro-scale catchment and comparison with field data using geostatistics, Phys. Chem. Earth, 28, 239-245, 10.1016/s1474-7065(03)00033-0, 2003.

Herbst, M., Diekkrüger, B., and Vanderborght, J.: Numerical experiments on the sensitivity of runoff generation to the spatial variation of soil hydraulic properties, J. Hydrol., 326, 43-58, 2006.

Jawson, S. D., and Niemann, J. D.: Spatial patterns from EOF analysis of soil moisture at a large scale and their dependence on soil, land-use, and topographic properties, Adv. Water Resour., 30, 366-381, 2007.

Jaynes, D. B., Kaspar, T. C., Colvin, T. S., and James, D. E.: Cluster analysis of spatiotemporal corn yield patterns in an Iowa field, Agron. J., 95, 574-586, 2003.

Jolliffe, I. T.: Principal Component Analysis, 2nd edn., Springer, New York, USA, 487 pp., 2002.

Kim, G. and Barros, A. P.: Space-time characterization of soil moisture from passive microwave remotely sensed imagery and ancillary data, Remote Sens. Environ., 81, 393-403, 2002.

Kitanidis, P. K. and Bras, R. L.: Real-Time Forecasting with A Conceptual Hydrologic Model .1. Analysis of Uncertainty, Water Resour. Res., 16, 1025-1033, 1980.

Koyama, C. N., Korres, W., Fiener, P., and Schneider, K.: Variability of Surface Soil Moisture Observed from Multi-temporal Cband SAR and Field Data, Vadose Zone J., V09-0165, in press, 2010.

Lorenz, E. N.: Empirical Orthogonal Functions and Statistical Weather Prediction, Department of Meteorology, MIT, 49, 1956.

Moore, I. D., Burch, G. J., and Mackenzie, D. H.: Topographic Effects on the Distribution of Surface Soil-Water and the Location of Ephemeral Gullies, T. Asae, 31, 1098-1107, 1988.

Moran, P. A. P.: Notes on continuous stochastic phenomena, Biometrika, 37, 17-23, 1950.

North, G. R., Bell, T. L., Cahalan, R. F., and Moeng, F. J.: Sampling Errors in the Estimation of Empirical Orthogonal Functions, Mon. Weather Rev., 110, 699-706, 1982.

Ntelekos, A. A., Georgakakos, K. P., and Krajewski, W. F.: On the uncertainties of flash flood guidance: Toward probabilistic forecasting of flash floods, J. Hydrometeorol., 7, 896-915, 2006.

Oppelt, N. M., Schneider, K., and Mauser, W.: Mesoscale soil moisture patterns derived from ERS data, Proc. SPIE, 3499, 41-51, doi:10.1117/12.332775, 1998.
Owe, M. and Van de Griend, A. A.: Comparison of Soil Moisture Penetration Depths for Several Bare Soils at Two Microwave Frequencies and Implications for Remote Sensing, Water Resour. Res., 34(9), 2319-2327, doi:10.1029/98wr01469, 1998.

Perry, M. A. and Niemann, J. D.: Analysis and estimation of soil moisture at the catchment scale using EOFs, J. Hydrol., 334, 388-404, 2007.

Preisendorfer, R. W.: Principal Component Analysis in Meteorology and Oceanography, Developments in Atmospheric Science, Elsevier, Amsterdam, 425 pp., 1988.

Schneider, K.: Assimilating remote sensing data into a land-surface process model, Int. J. Remote Sens., 24, 2959-2980, 2003.

Vachaud, G., Desilans, A. P., Balabanis, P., and Vauclin, M.: Temporal Stability of Spatially Measured Soil-Water Probability Density-Function, Soil Sci. Soc. Am. J., 49, 822-828, 1985.

Vereecken, H., Kamai, T., Harter, T., Kasteel, R., Hopmans, J., and Vanderborght, J.: Explaining soil moisture variability as a function of mean soil moisture: A stochastic unsaturated flow perspective, Geophys. Res Lett., 34, L22402, doi:10.1029/2007gl031813, 2007.

Western, A. W. and Grayson, R. B.: The Tarrawarra data set: Soil moisture patterns, soil characteristics, and hydrological flux measurements, Water Resour. Res., 34, 2765-2768, 1998.

Western, A. W., Blöschl, G., and Grayson, R. B.: Geostatistical characterisation of soil moisture patterns in the Tarrawarra a catchment, J. Hydrol., 205, 20-37, 1998.

Western, A. W., Grayson, R. B., and Green, T. R.: The Tarrawarra project: high resolution spatial measurement, modelling and analysis of soil moisture and hydrological response, Hydrol. Process., 13, 633-652, 1999a.

Western, A. W., Grayson, R. B., Blöschl, G., Willgoose, G. R., and McMahon, T. A.: Observed spatial organization of soil moisture and its relation to terrain indices, Water Resour. Res., 35, 797810, 1999 b.

Western, A. W., Blöschl, G., and Grayson, R. B.: Toward capturing hydrologically significant connectivity in spatial patterns, Water Resour. Res., 37, 83-97, 2001.

Western, A. W., Zhou, S. L., Grayson, R. B., McMahon, T. A., Blöschl, G., and Wilson, D. J.: Spatial correlation of soil moisture in small catchments and its relationship to dominant spatial hydrological processes, J. Hydrol., 286, 113-134, 2004.

Yoo, C. and Kim, S.: EOF analysis of surface soil moisture field variability, Adv. Water Resour., 27, 831-842, 2004.

Zaslavsky, D. and Sinai, G.: Surface Hydrology 1, Explanation of Phenomena, J. Hydr. Eng. Div.-ASCE, 107, 1-16, 1981. 